\title{
Differentiation of Human Embryonic Stem Cells towards a Sensory Neural Phenotype
}

\author{
Rouknuddin Qasim $\mathrm{Ali}^{1}$, Yen-Fu Cheng ${ }^{1}$, Beata Kostyszyn ${ }^{1}$, Lars Ährlund-Richter ${ }^{2}$ \\ and Mats Ulfendahl ${ }^{1}$ \\ ${ }^{1}$ Department of Neuroscience, Karolinskalnstitutet, Stockholm, Sweden \\ ${ }^{2}$ Department of Women's and Children's Health, Karolinskalnstitutet, Stockholm, Sweden
}

Correspondence should be addressed to: Rouknuddin QasimAli; rouknuddin.ali@ki.se, mats.ulfendahl@ki.se

Received Date: 18 February 2014; Accepted Date: 10 June 2014; Published Date: 30 June 2014

Academic Editor: Victoria Moreno-Manzano

Copyright (C) 2014 Rouknuddin Qasim Ali, Yen-Fu Cheng, Beata Kostyszyn, Lars Ährlund-Richter and Mats Ulfendahl. Distributed under Creative Commons CC-BY 3.0

\begin{abstract}
Sensorineural hearing loss, caused by the degeneration of inner ear sensory hair cells or afferent auditory neurons, is a major problem in clinical medicine. In birds and lower vertebrates, regeneration of these cells may occur but in mammals, the loss is irreversible. In this study, neuronal progenitors were derived from human embryonic stem cells in the form of neural tube-like rosettes and harvested enzymatically after 4 days (NS4), 7 days (NS7) or 11 days (NS11). This was followed by a further differentiation on laminin-coated plates for 1 or 3 weeks in neural induction medium without bFGF. Such cultures were all dominated by cells immunoreactive for nestin, a common neuronal progenitor marker, as well as for Tuj1, an early marker for neurons.
\end{abstract}

Among the combinations tested, the NS7 +1 week protocol showed the most abundant induction of the sensory neuron markers TrkC $(20 \%)$ and peripherin (11\%), making this protocol the most favorable for the induction of sensory neurons. Compared with other published more complex protocol requiring the addition of different growth factors, the straightforward approach described here may contribute with a simplified starting point for the further exploration of novel approaches for in vitro generation of sensory neurons, and ultimately the treatment of sensory hearing impairment using cell transplantation.

Keywords: hESC, sensory neurons, in-vitro.

\section{Introduction}

The World Health Organization (WHO) estimates that nearly 300 million people worldwide have moderate to profound hearing loss affecting both ears. Hearing impairment is either conductive or sensorineural. Whereas conductive hearing impairment, caused by defects in the outer or middle ear, can be relatively readily corrected, sensorineural hearing impairment constitutes much more of a clinical problem. The defects are most frequently to be found within the inner ear sensory epithelium, or occasionally related to the auditory neurons and their afferent fibers. In birds and other non-mammalian species, sensory cells can be regenerated 
even after severe damage (Corwin and Cotanche, 1988, Stone and Cotanche, 2007). However, in humans and other mammals the loss is permanent. Besides traditional hearing aids, the most innovative approach to rehabilitate severely hearing-impaired individuals is the cochlear implant. Essentially, the cochlear implant by-passes the malfunctioning sensory hair cells and directly stimulate the remaining auditory neurons, thus exciting the auditory pathways and eliciting a sound perception. Cochlear implant function depends partly on the presence of a sufficiently large population of healthy auditory neurons. It has been proposed that the efficacy of a cochlear implant could be enhanced by a cell therapy approach aiming at increasing the neuronal population in the damaged inner ear (Hu and Ulfendahl, 2006, Ulfendahl et al., 2007). Advancements in molecular and cellular therapies using cells derived from pluripotent stem cells are emerging as potential tools for developing new treatment strategies for restoring auditory function (Reyes et al., 2008, Valensi-Kurtz et al., 2010, Chen et al., 2012, Nayagam and Minter, 2012).

Human embryonic stem cells (hESC) have the potential to form all types of cells and are thus of great interest for regenerative medicine. Their potential for providing an unlimited supply of various cell types(Heins et al., 2004, Reubinoff et al., 2000) provides a possible opportunity to selectively produce cells for specialized sensory systems such as the inner ear. Recently, neuronal differentiation has been performed using hESC cells, mainly focusing on neurons of the central nervous system (CNS) with clinical implications for future cell-based therapies for neurodegenerative diseases e.g., Parkinson and multiple sclerosis. However, very few reports focus on peripheral nervous system (PNS) neurons. (Erceg et al., 2009, Chambers et al., 2012, Brokhman et al., 2008, Pomp et al., 2005, Shi et al., 2007).

Neural crest cells are important for the formation of peripheral nervous system
(PNS) and studies in vitro have demonstrated that hESC derived neural crest cells can give rise to both sensory and autonomic neurons as well as glial cells (Christiansen et al., 2000). During neural tube closure neural crest cells migrate out and differentiate into neurons, melanocytes and the facial skeleton. Several protocols have been developed with the aim of enhancing the differentiation of neural crest cells towards a neural fate. These protocols generally include the formation of embryoid bodies (EBs), and the use of conditioned media, exogenous factors and stromal cell lines (Carpenter et al., 2001, Schuldiner et al., 2001, Buytaert-Hoefen et al., 2004, Itsykson et al., 2005).

With the long-term aim of restoring or, at least facilitating, auditory function using a cell therapy approach, it is of interest to establish protocols promoting differentiation into sensory neurons. Recently, it has been shown that hESC and induced pluripotent stem cells (iPSC) can be differentiated in otic neural progenitors and when transplanted into animals, can restore hearing (Chen et al., 2012).

With the aim of shortening the generation time and to simplify the protocol, we here evaluate the generation of a sensory neuron phenotype using protocols based on different time stages of hESC derived neural tube-like rosettes.

\section{Materials and Methods}

\section{Experimental Design}

The general experimental design is illustrated in Figure 1. In brief, hESC derived EBs were allowed to differentiate into neuronal progenitors (NP), as neural tube like structures (neural rosettes) over a period of 4,7 , or 11 days when cultured on laminin coated plates in neural induction medium (NIM) supplemented with bFGF. NP cells were then enzymatic/mechanically extracted and further cultured for 1 or 3 weeks in NIM medium, with the aim of exploring differentiation into peripheral sensory like neurons. 


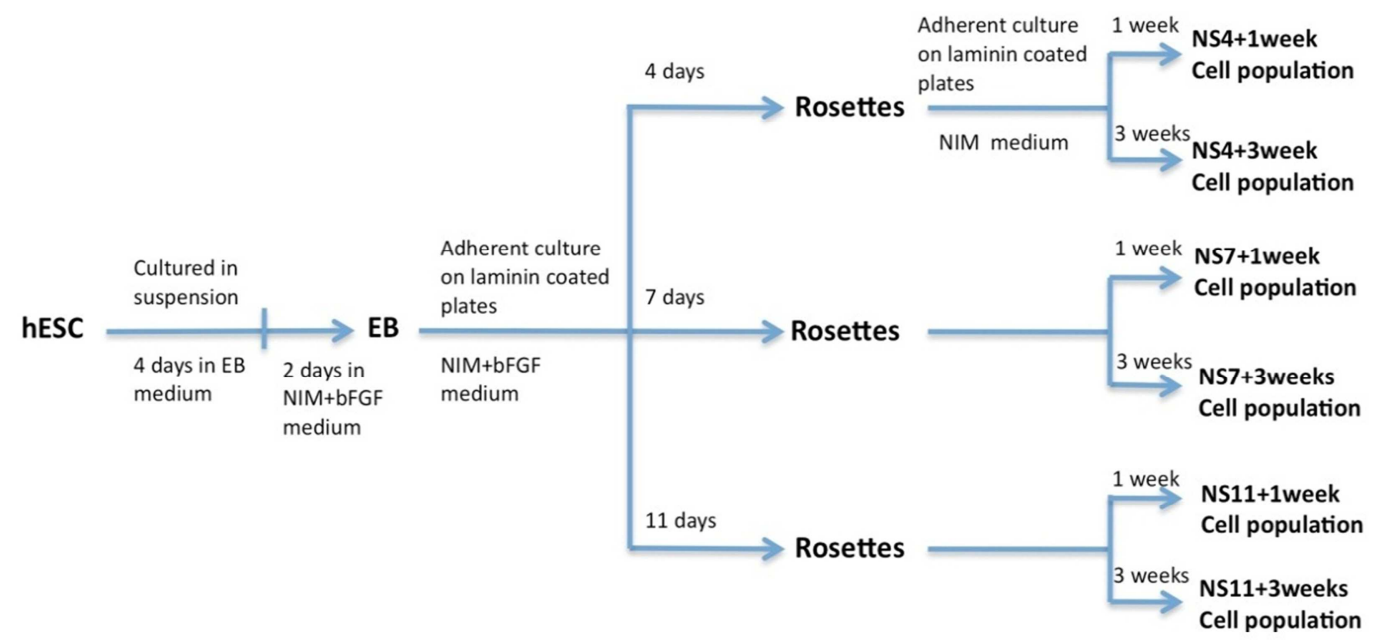

\section{Figure 1. Schematic overview of the protocols used for the induction of sensory neurons.}

Human embryonic stem cells were cultured in suspension for 4 days in EB medium, then for 2 days in NIM medium containing bFGF to generate EBs. EBs were cultured adherently on lamanincoated plates for 4, 7 and 11 days on NIM medium with bFGF. Neural rosettes were subsequently re-plated for 1 week or 3 weeks in NIM medium, to differentiate into PSN.

\section{Generation of Neural Progenitor's In- Vitro}

\section{EB Formation}

A human embryonic stem cell (hESC) line, HS181, was used in the present study. The HS181 cell line was maintained as previously described using human fibroblast feeder cells (Hovatta et al., 2003, Imreh et al., 2004). Colonies of undifferentiated hESC were detached by dispase and resuspended in EB medium consisting of $80 \%$ Knock Out-Dulbecco's Modified Eagle Medium (KO-DMEM), 20\% Knock Out-Serum Replacement (KO-SR), 2 mM L-glutamine, 1\% nonessential amino acids, and $0.1 \mathrm{mM} ß$-mercapoethanol (all reagents obtained from Invitrogen $A B$, Stockholm, Sweden). The cells were cultured in 60-mm culture dishes (BD Falcon) with daily changes of medium. Next day, embryoid bodies (EBs) were transferred into new culture dishes in order to remove remaining unattached feeder cells. After 4 days in EB medium, the
EBs were again transferred into new culture dishes and cultured for 2 more days in neural induction medium (NIM) supplemented with $20 \mathrm{ng} / \mathrm{ml}$ bFGF. Neural induction medium consisted of KO-DMEM plus N2 supplement (Invitrogen $A B$, Stockholm, Sweden), $2 \mathrm{mM}$ L-glutamine and $1 \%$ nonessential amino acids.

\section{Generation of Neurospheres from hESC Derived EBs}

The 6-day EB cultures were plated into 4well plates (Nuclon) pre-coated with 20 $\mu \mathrm{g} / \mathrm{mL}$ laminin (Sigma; cat. no. L2020; dissolved in $\mathrm{PBS}$ overnight at $37^{\circ} \mathrm{C}$ ), and further cultured in NIM with bFGF.

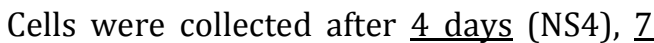
days (NS7) or 11 days (NS11), using Dispase $(0.5 \mathrm{mg} / \mathrm{ml})$ for $15-20$ minutes to dissociate neural rosettes from surrounding non-neural structures. The dissociated neural rosettes were re-plated in 6-well plates in NIM and most nonneural cells adhered to the culture plates 
within one hour, while floating clumps of neural cells could be readily isolated. These clumps (neurospheres) were related to laminin coated 4-well cultures plates for a period of 1 or 3 weeks in NIM. Half of the culture medium was replaced every second day.

\section{Immunocytochemistry}

The cells were fixed in 4\% neutral buffered paraformaldehyde at room temperature for 20 minutes, incubated in PBS-Ca/Mg with $10 \%$ fetal bovine serum (FBS) (fraction V, Sigma) plus $0.1 \%$ Tween-20 at room temperature for 30 minutes. Primary antibodies against the following proteins were used: nestin (polyclonal rabbit antibody; Abcam; ab5968-100, 1:500; and monoclonal antibody; Chemicon; MAB5326, 1:200), Tuj1 (neuron-specific class III beta-tubulin; polyclonal rabbit antibody; Covance; PRB-435P, 1:500; and monoclonal antibody; Covance; MMS-435P, 1:500), Ki67 (mouse monoclonal antibody; Abcan; ab6526, 1:200), Cleaved caspase-3 (polyclonal rabbit antibody; Cell signaling; 9661S, 1:200), peripherin (polyclonal rabbit antibody; Chemicon; AB1530, 1:200; and monoclonal antibody; Chemicon; MAB5380, 1:200), TrkB (polyclonal rabbit antibody; Santa Cruz; sc-8316, 1:200) and TrkC (polyclonal rabbit antibody; Santa Cruz; sc-117, 1:200). The antibodies were diluted in PBS-Ca/Mg $+0.1 \%$ Tween-20 + $10 \% \mathrm{FBS}$ at $4^{\circ} \mathrm{C}$ overnight. The cells were washed three times in PBS- $\mathrm{Ca} / \mathrm{Mg}$ and incubated with anti-rabbit and goat antimouse secondary antibodies conjugated to AlexaFluor 594 or AlexaFluor 488 (1:200, Invitrogen), at room temperature for 2 hours. After washing, the cell plates were mounted with Vectashield containing DAPI (Vector labs Inc., Burlingame, CA, Cat. No. $\mathrm{H}-1200$ ) and observed using fluorescence microscopy (Carl Zeiss).

\section{Visualization and Quantification of Cellular Immunocytochemistry Markers}

All fluorescent microscopic images were captured by Axiovision (Carl Zeiss, Germany). Quantification was done at 40X magnification images from 4 independent experiments. Each experiment was performed in duplicate and 5-6 randomly chosen fields were counted. 500 to 600 cells were counted from each experiment. Numbers of positive cells were quantified using custom written macros based on Otsu thresholding in ImageJ software $(\mathrm{NIH}$, Bethesda, MD).

\section{$\underline{\text { Statistical Analysis }}$}

All data were processed using Graphpad prism software. For quantification procedures, statistical differences were performed by one-way ANOVA with Newman-keuls multiple comparison test to determine the level of significance and unpaired t-test was done between two groups.

\section{Results and Discussion}

\section{Differentiation into Neuronal Progenitors (NP).}

Neural crest cells are known to ascend from the neural tube. Immediately after neural tube closure they migrate out to form the peripheral nervous system, including the sensory neurons formed in the otic region starting around Carnegie stage 10-12 in human embryo (O'Rahilly, 1987). Cells of the oticplacode share similar developmental origin with neural crest stem cells, and also a comparable molecular machinery for controlling their maturation and differentiation (Huisman and Rivolta, 2012).

In a reminiscent in vitro model, human embryonic stem cells have been shown to differentiate into neural tube-like structures with radial arrangements of columnar cells, rosettes, expressing many of the proteins present in neuroepithelial cells in the neural tube (Wilson and Stice, 2006, Curchoe et al., 2012). Pluripotent stem cells, ESC and iPSC have shown a gradual lineage restriction during neuronal differentiation and variety of distinctive progenitors can be generated. Here we study a spontaneous further differentiation from such rosettes into cells having a marker profile of sensory neurons. FGFsignaling plays an important role in otic formation and development (Wright and 
Mansour, 2003), and it has been shown that bFGF is important in the differentiation of neural progenitors from hESC (Zhang et al., 2001, Stern, 2006). In the current study we have used bFGF to derive neural progenitors at different time points to assess their potential to differentiate into sensory neuron.

In line with previous reports (Zhang et al., 2001, Erceg et al., 2008), visual analysis revealed from day 3 and onwards a migration of cells out from the centers of the EBs cell clusters into radial arrangements of elongated columnar cells, surrounded by flat epithelial cells (Fig. 2 A). At day 4, elongated columnar cells occurred at the center of differentiating EBs, now forming 'rosettes' (NS4; Fig. 2 B) similar to what has previously been described as primitive neural ectoderm (Wilson and Stice, 2006). This development was further accentuated on days 7 (NS7) and 11 (NS11) (Fig. 2, C-D). Also in line with previous studies (Zhang et al., 2001, Li et al., 2005, Shi et al., 2007), we showed positive staining for nestin and Tuj1 in such neural rosettes at all tested time points, supporting the presence of early neuronal cells (Fig. 3A-F).
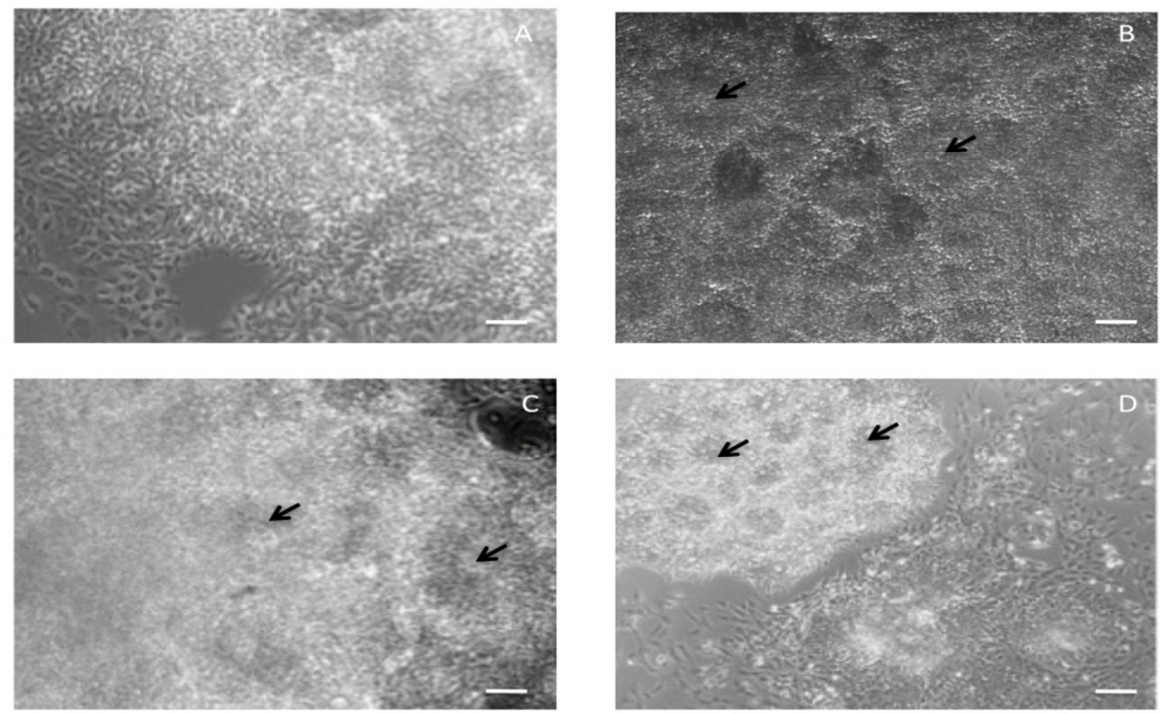

Figure 2. Phase contrast images of neural rosette formation.

Development of neural rosettes after plating 6 days EB's on laminine coated plates. After 3 days (A), EBs were attached and cells were seen to migrate out from the center and to be surrounded by flat cells at the periphery. After 4 days (B), 7 days (C) and 11 days (D), neural rosettes structure started to appear in the center (black arrows), resembling the primitive neural ectoderm. Magnification is $10 \mathrm{X}$ and scale $\mathrm{bar}=200 \mu \mathrm{m}$ (A-D)

\section{Differentiation into Peripheral Sensory Neurons}

With the objective to achieve further differentiation towards sensory neurons, floating neurospheres were isolated from the NS4, NS7 and NS11 cultures and allowed to attach on laminin-coated plates for an additional one- or three-week period of culture. Immunostaining demonstrated that after one week of further culture, high levels of nestin positive cells were found in all cultures (97\%; 92\%; 88\%, respectively). However, significant drops of nestin positive cells were noted after prolonged culture in the NS4 + 3 weeks and the NS7 + 3 weeks cultures $(48 \%$ and $49 \%$, respectively; $\mathrm{p}<0.05$; Fig. 4 ), but not in the NS11 + 3 weeks cultures (89\%; NS. Fig. 4). 


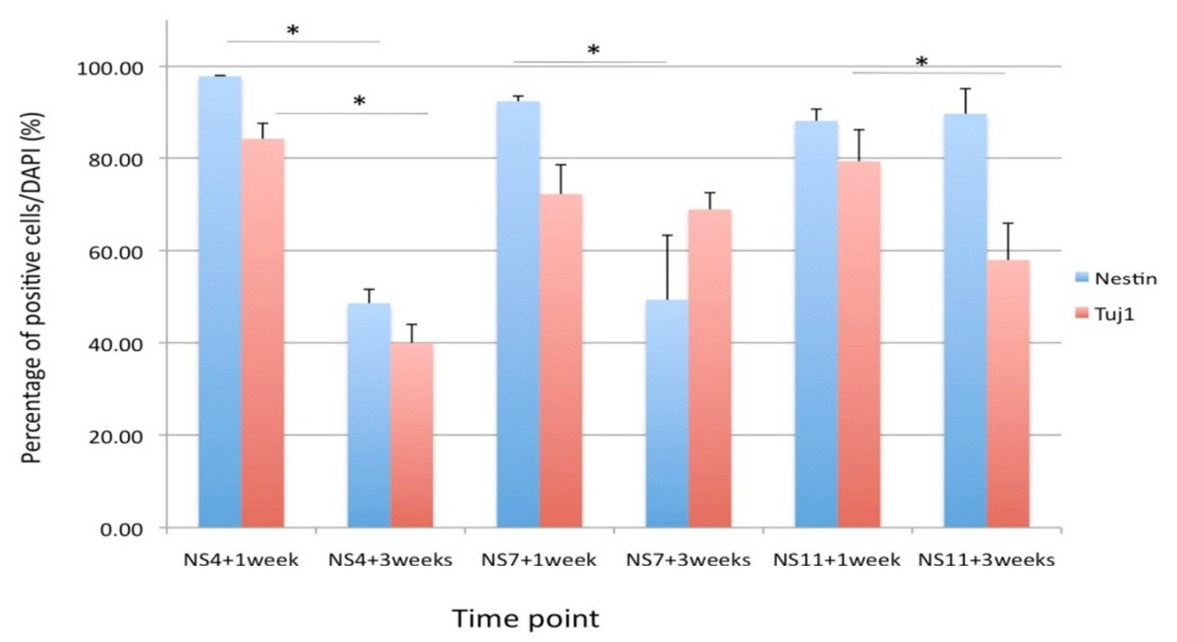

Figure 4. Quantitative analysis of number of cells immunoreactive for nestin and Tuj1 at different time points. The frequencies of nestin positive cells in the NS4 and NS7 cell populations were lower after 3 weeks compared to after 1 week $(p<0.05)$. No differences in nestin stainig were observed for the NS11 cell populations. Tuj1 immunoreactivity showed significant decrease in number of positive cells in NS4 and NS11 cell populations after 3 weeks compared to 1 week $(p<0.05)$, whereas no difference was seen for the NS7 cell population. Average from four experiments. Bars indicate standard error mean (SEM).

The expression of Tuj1 was increased after one week in NS4 + 1 week (84\%), NS7 + 1 week (72\%) and NS11 + 1 week (79\%) cultures, but showed a significant drop in the NS4 + 3 weeks (40\%) and in the NS11 + 3 weeks (57\%) cultures ( $p<0.05$; Fig. 4). The NS7 cultures showed however equivalent levels of Tuj1 cells after one and three weeks (72\% versus 69\%; NS).

Thus, diverging results with regard to reductions of the nestin and Tuj1 after prolonged culture were observed, possibly reflecting a differential loss of early neural progenitors.

We investigated the cultures for proliferation and apoptosis. Staining for
Ki67 indicated a similar proliferative capacity for the NS4 $(33.6 \pm 2.6 \%)$, NS7 $(32.4 \pm 2.3 \%)$ and NS11 cultures $(30.5 \pm 2.4 \%)$. The expression of cleaved caspase 3 revealed a higher degree of apoptosis in the prolonged NS11 cultures $(15.3 \pm 2.9 \%)$ versus NS4 (10.2 $\pm 1.7 \%)$ and NS7 $(11.4 \pm 1.1 \%)(p<0.05)$. This could possibly be explained by the presence of a more mature neuronal population in NS11 population, as indicated by the Tuj1 staining (Fig. $3 \mathrm{~F}$ ), compared to the NS4 (Fig. 3 B) and NS7 cultures (Fig. 3D). 

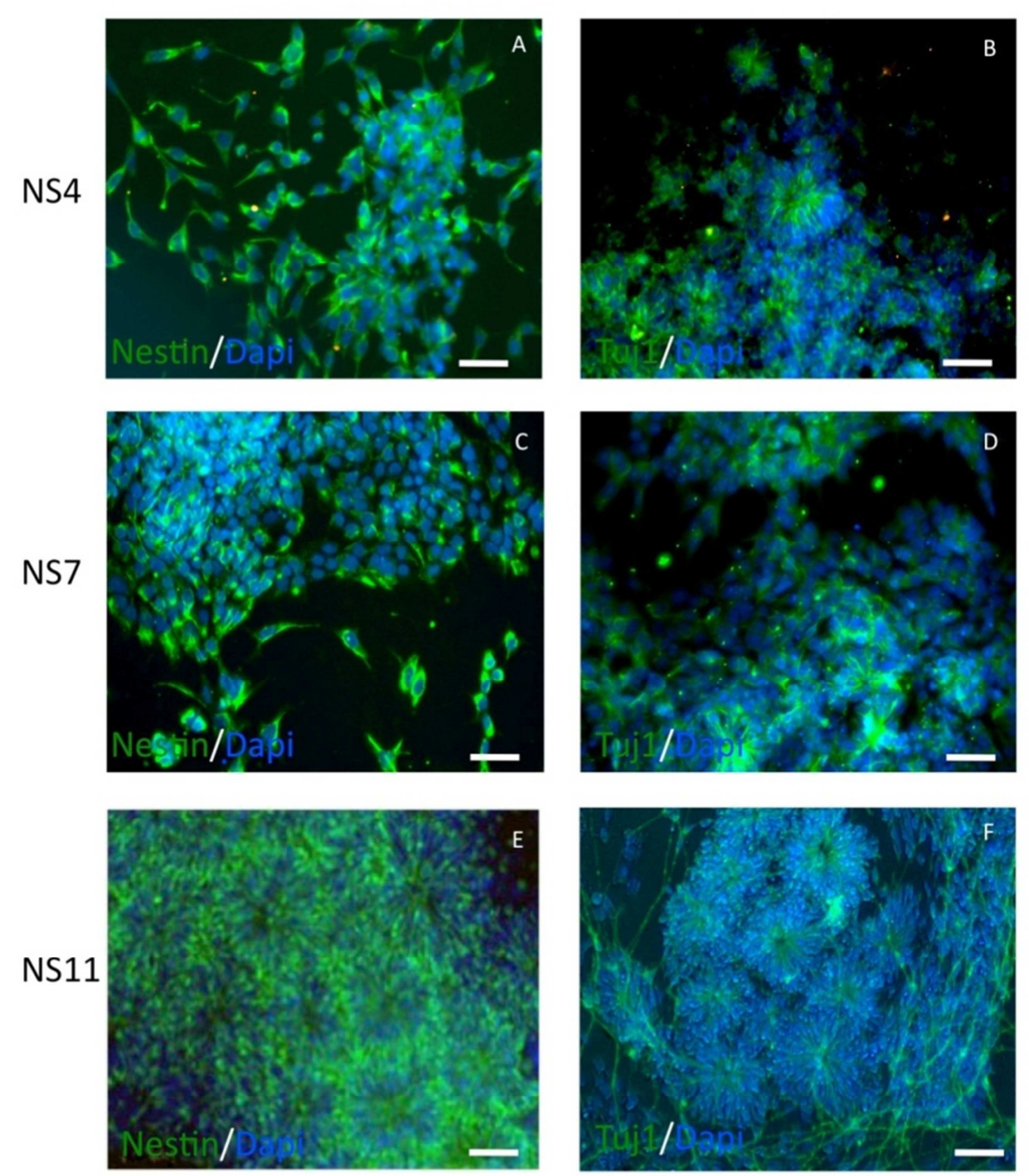

Figure 3. Immunostaining of neural rosettes.

Neural rosettes derived from EB cultured on laminin-coated plates for 4,7 or 11 days. Cells were stained with nestin $(A, C, E)$, Tuj1 (B, D, F) and counterstained with DAPI. Robust staining is observed for nestin (early neural progenitor marker) and Tuj1 (early marker for neuronal cells). Magnification is 20X and scale bar $=50 \mu \mathrm{m}(\mathrm{A}-\mathrm{F})$.

In continued experiments, the development of sensory neuron was assessed by a combined expression of Tuj1 with peripherin (an intermediate filament protein found in peripheral axons (Troy et al., 1990)), as well as expression of TrkB, and TrkC (two receptor proteins expressed in sensory neurons (Schimmang et al.,
1995, Postigo et al., 2002)). The results of these experiments are summarized in Figure 5. Co-localization of these sensory neural markers was seen mostly in bipolar neurons, structurally resembling the bipolar auditory spiral ganglion cells (Fig. 6). 


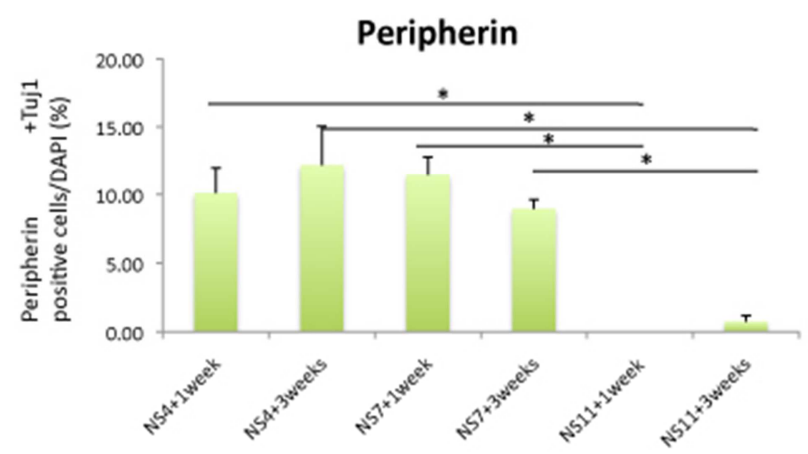

TrkB

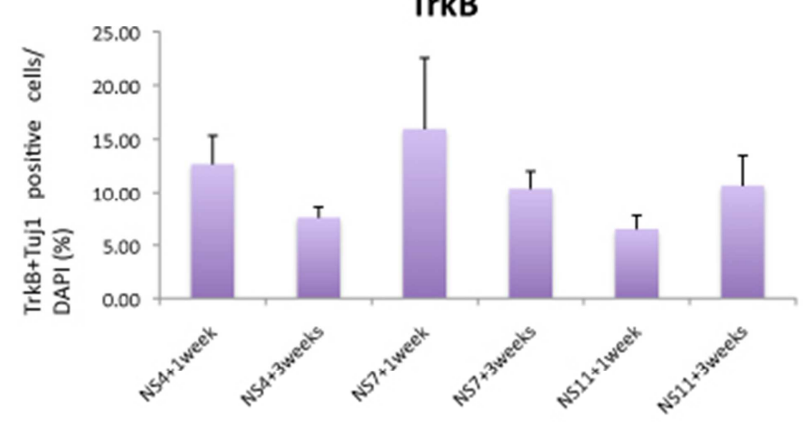

TrkC

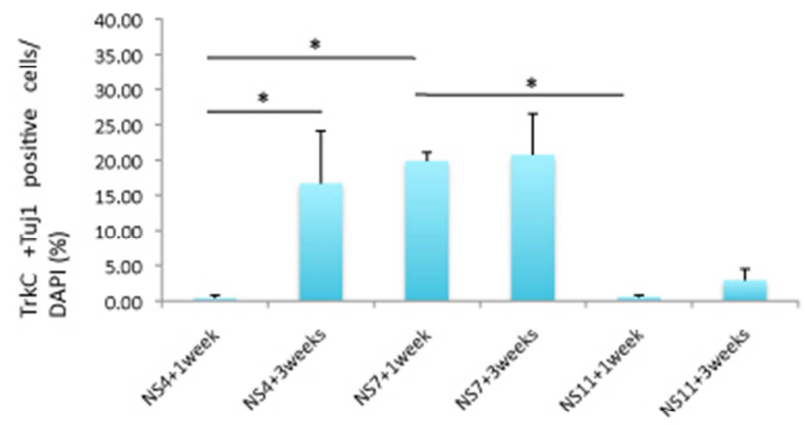

Time points

Figure 5. Quantitative analysis of total number of cells positive for peripherin, TrkB and TrkC

The frequencies of cells positive for peripherin were similar in the NS4 and NS7 populations, while NS11 showed significantly lower numbers $(p<0.05)$. The frequencies of TrkB staining were similar in NS4, NS7 and NS11 populations whereas TrkC staining showed significantly higher numbers of positive cells in NS7+1 compared to NS4+1 and NS11+1 ( $<<0.05)$. Average from four experiments. Bars indicate standard error mean (SEM). 

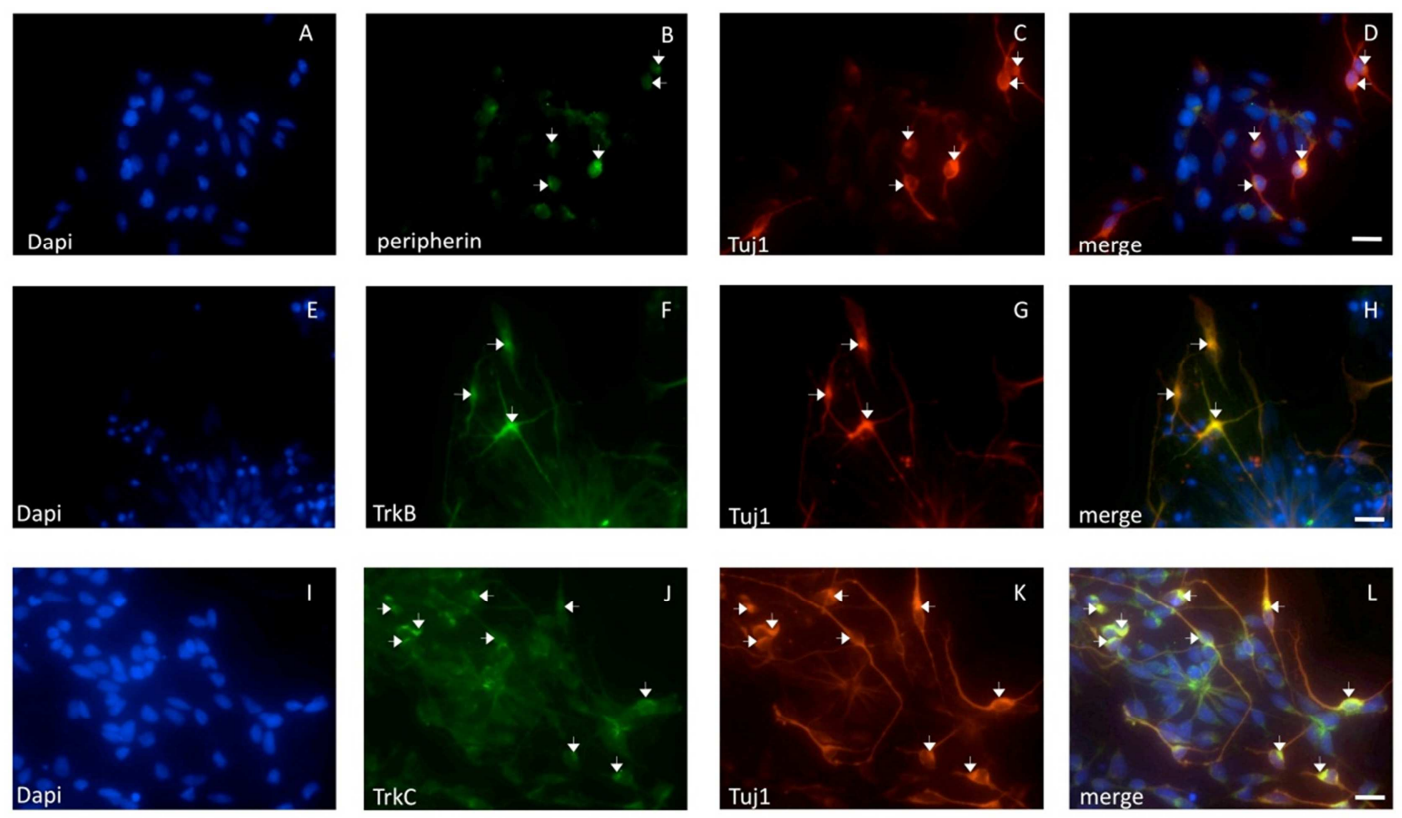

Figure 6. Immunostaining of NS7 rosettes after 1 week

NS7 rosettes were cultured for 1 week and stained for Tuj1 (C, G, K) in combination with peripherin (B), TrkB (F) or TrkC (J). Merged pictures in $D, H, L$ respectively. Arrows indicate cells with double staining for Tuj1 together with peripherin (B); TrkB (F) or TrkC (J). Counterstaining was performed using DAPI. Magnification is 40X and scale bar $=20 \mu \mathrm{m}$.

The occurrence of peripherin positive cells was similar in all NS4 and NS7 cell populations (ranging between 9-12\%), but significantly lower in the NS11 cell population $(<1 \%)(\mathrm{p}<0.05$; Fig. 5$)$. TrkB and TrkC are receptors for the neurotrophic factor (BDNF or NT3), and expression is important for sensory neurons during auditory system development (Schimmang et al., 1995). Data from in-situ hybridization have shown that both TrkB and TrkC are synthesized in cochlear ganglion neurons and that the deletion of the gene for TrkB or TrkC results in the complete loss of ganglionic neurons (reviewed by (Rubel and Fritzsch, 2002). The TrkB marker did not differentiate the three protocols when tested at one week (NS4, 13\%; NS7, 16\%: NS11, 7\%), or three weeks (NS4, 8\%; NS7, 10\%: NS11, 11\%) (Fig. 5). However, the presence of cells positive for TrkC was significantly increased by the three weeks additional culture of NS4 $(<1 \%$ versus 17\%; $\mathrm{p}<0.05)$. Furthermore, the NS7 protocol showed the highest frequency, $20 \%$, of TrkC cells, both after one week and three weeks of culture. The NS7 results thus contrast strongly with the NS11 cultures in which TrkC cells were very scarce after one week $(<1 \%)$ and three weeks $(3 \%)$. TrkC positive cells were significantly increased in NS7 +1 cultures compared to NS4 +1 , and NS11 + 1 cultures (Fig. 5)

A low occurrence of sensory neurons in the NS11 populations was also indicated by the negligible presence of peripherin positive cells, after both one and three weeks $(<1 \%)$. Experiments using mouse ESC, differentiated as monolayers, have shown that neural progenitors lose their neurogenic potential during longer duration (Abranches et al., 2009). This notion is supported by our observation that the NS11 cell population displayed a reduced ability to differentiate into sensory neurons whereas the NS4 and NS7 groups maintained this differentiation potential.

The observed levels of peripherin positive cells using NS4 and NS7 (range 9-12\%) are similar to that shown by Shi et al., (Shi et al., 2007) who reported a frequency of $15.5 \%$ using BMP4. They obtained however less than $2 \%$ peripherin positive cells from cultures with bFGF. Our protocol did 
however not reach the high levels of 40 $75 \%$ peripherin positive neurons found in hESC culture induced with small molecules (Lee et al., 2010, Chambers et al., 2012). Other reported protocols yielded about $10 \%$ peripheral neurons when neural progenitor cells, as starting cell populations, were cultured on PA6 stromal cell feeders, and less than $1 \%$ of peripheral neurons when starting from hESC (Pomp et al., 2005, Brokhman et al., 2008).

\section{Conclusions}

Based on the sensory neuron markers TrkC and peripherin we conclude that out of the three tested protocols the NS7 + 1 protocol was the most favorable for the induction of sensory neurons.The NS7+1 culture conditions yielded an induction of up to $11 \%$ peripherin and $20 \%$ TrkC positive cells $(\mathrm{p}<0.05)$. No further induction was obtained using the NS7+3protocol.

The presented model system allows for the characterization of the relevant cellular functions as well as developing the tools necessary to generate sufficient number of functional sensory neurons that could be explored for a cell therapy approach. In addition, the protocol is simplified compared to other published protocol where different growth factors were added.

Next, cells differentiated according to the protocols presented here are to be tested for their capacity to integrate with auditory tissue and thus to explore the potential of a cell therapy based treatment of sensorineural hearing loss.

\section{Acknowledgements}

This work was supported by the European Commission (MU FP6 Integrated Project EUROHEAR; contract grant number: LSHGCT-20054-512063), the Swedish Research Council (MU grant nr 2010-7209, LAR grant $\mathrm{nr}$ K2008-55X-2034-01-3), the TystaSkolan Foundation (MU), the Petrus and Augusta Hedlund Foundation (MU and LAR), the KI-RGD network (LAR), and in part by the AFA insurance company (dnr 110024; MU). Rouknuddin Ali was supported by a stipend from the Higher Education Commission of Pakistan (RA). Yen-Fu Cheng was the recipient of a scholarship from the Yen Tjing Ling Medical Foundation, Taiwan

\section{References}

Abranches, E., Silva, M., Pradier, L., Schulz, H., Hummel, O., Henrique, D. \& Bekman, E. (2009). "Neural Differentiation of Embryonic Stem Cells in Vitro: A Road Map to Neurogenesis in the Embryo," PloS One, 4, E6286.

Brokhman, I., Gamarnik-Ziegler, L., Pomp, O., Aharonowiz, M., Reubinoff, B. E. \& Goldstein, R. S. (2008). "Peripheral Sensory Neurons Differentiate from Neural Precursors Derived from Human Embryonic Stem Cells," Differentiation, 76, 145-155.

Buytaert-Hoefen, K. A., Alvarez, E. \& Freed, C. R. (2004). "Generation of Tyrosine Hydroxylase Positive Neurons from Human Embryonic Stem Cells after Coculture with Cellular Substrates and Exposure to Gdnf," Stem Cells, 22, 669-674.

Carpenter, M. K., Inokuma, M. S., Denham, J., Mujtaba, T., Chiu, C. P. \& Rao, M. S. (2001). "Enrichment of Neurons and Neural Precursors from Human Embryonic Stem Cells," Experimental Neurology, 172, 383397.

Chambers, S. M., Qi, Y., Mica, Y., Lee, G., Zhang, X. J., Niu, L., Bilsland, J., Cao, L., Stevens, E., Whiting, P., Shi, S. H. \& Studer, L. (2012). "Combined Small-Molecule Inhibition Accelerates Developmental Timing and Converts Human Pluripotent Stem Cells into Nociceptors," Nature Biotechnology, 30, 715-20.

Chen, W., Jongkamonwiwat, N., Abbas, L., Eshtan, S. J., Johnson, S. L., Kuhn, S., Milo, M., Thurlow, J. K., Andrews, P. W., Marcotti, W., Moore, H. D. \& Rivolta, M. N. (2012). "Restoration of Auditory Evoked Responses by Human ES-cell-derived Otic Progenitors," Nature, 490, 278-82. 
Christiansen, J. H., Goles, E. G. \& Wilkinson, D. G. (2000). "Molecular Control of Neural Crest Formation, Migration and Differentiation," Current Opinion in Cell Biology, 12, 719-724.

Corwin, J. T. \& Cotanche, D. A. (1988). "Regeneration of Sensory Hair Cells after Acoustic Trauma," Science, 240, 1772-4.

Curchoe, C. L., Russo, J. \& Terskikh, A. V. (2012). "Hesc Derived Neuro-Epithelial Rosettes Recapitulate Early Mammalian Neurulation Events; an in Vitro Model," Stem Cell Research, 8, 239-46.

Erceg, S., Lainez, S., Ronaghi, M., Stojkovic, P., Perez-Arago, M. A., Moreno-Manzano, V., Moreno-Palanques, R., Planells-Cases, R. \& Stojkovic, M. (2008). "Differentiation of Human Embryonic Stem Cells to Regional Specific Neural Precursors in Chemically Defined Medium Conditions," PloS One, 3.

Erceg, S., Ronaghi, M. \& Stojkovic, M. (2009). "Human Embryonic Stem Cell Differentiation toward Regional Specific Neural Precursors," Stem Cells, 27, 78-87.

Heins, N., Englund, M. C. O., Sjoblom, C., Dahl, U., Tonning, A., Bergh, C., Lindahl, A., Hanson, C. \& Semb, H. (2004). "Derivation, Characterization, and Differentiation of Human Embryonic Stem Cells," Stem Cells, $22,367-376$.

Hovatta, O., Mikkola, M., Gertow, K., Stromberg, A. M., Inzunza, J., Hreinsson, J., Rozell, B., Blennow, E., Andang, M. \& Ahrlund-Richter, L. (2003). "A Culture System Using Human Foreskin Fibroblasts as Feeder Cells Allows Production of Human Embryonic Stem Cells," Human Reproduction, 18, 1404-1409.

Hu, Z. \& Ulfendahl, M. (2006). "Cell Replacement Therapy in the Inner Ear," Stem Cells and Development, 15, 449-59.

Huisman, M. A. \& Rivolta, M. N. (2012). "Neural Crest Stem Cells and Their Potential Application in a Therapy for Deafness," Frontiers in Bioscience (Scholar Edition), 4, 121-32.
Imreh, M. P., Wolbank, S., Unger, C., Gertow, K., Aints, A., Szeles, A., Imreh, S., Hovatta, O., Fried, G., Dilber, S. \& Ahrlund-Richter, L. (2004). "Culture and Expansion of the Human Embryonic Stem Cell Line HS181, Evaluated in a Double-Color System," Stem Cells and Development, 13, 337-343.

Itsykson, P., Ilouz, N., Turetsky, T., Goldstein, R. S., Pera, M. F., Fishbein, I., Segal, M. \& Reubinoff, B. E. (2005). "Derivation of Neural Precursors from Human Embryonic Stem Cells in the Presence of Noggin," Molecular and Cellular Neuroscience, 30, 24-36.

Lee, G., Chambers, S. M., Tomishima, M. J. \& Studer, L. (2010). "Derivation of Neural Crest Cells from Human Pluripotent Stem Cells," Nature Protocols, 5, 688-701.

Li, X. J., Du, Z. W., Zarnowska, E. D., Pankratz, M., Hansen, L. O., Pearce, R. A. \& Zhang, S. C. (2005). "Specification of Motoneurons from Human Embryonic Stem Cells," Nature Biotechnology, 23, 215221.

Nayagam, B. A. \& Minter, R. L. (2012). "A Comparison of in Vitro Treatments for Directing Stem Cells toward a Sensory Neural Fate," American Journal of Otolaryngology, 33, 37-46.

O'rahilly, R. (1987). "Human Embryo," Nature, 329, 385.

Pomp, O., Brokhman, I., Ben-Dor, I., Reubinoff, B. \& Goldstein, R. S. (2005). "Generation of Peripheral Sensory and Sympathetic Neurons and Neural Crest Cells from Human Embryonic Stem Cells," Stem Cells, 23, 923-930.

Postigo, A., Calella, A. M., Fritzsch, B., Knipper, M., Katz, D., Eilers, A., Schimmang, T., Lewin, G. R., Klein, R. \& Minichiello, L. (2002). "Distinct Requirements for TrkB and TrkC Signaling in Target Innervation by Sensory Neurons," Genes \& Development, 16, 633-645. 
Reubinoff, B. E., Pera, M. F., Fong, C. Y., Trounson, A. \& Bongso, A. (2000). "Embryonic Stem Cell Lines from Human Blastocysts: Somatic Differentiation in Vitro," Nature Biotechnology, 18, 399-404.

Reyes, J. H., O'shea, K. S., Wys, N. L., Velkey, J. M., Prieskorn, D. M., Wesolowski, K., Miller, J. M. \& Altschuler, R. A. (2008). "Glutamatergic Neuronal Differentiation of Mouse Embryonic Stem Cells after Transient Expression of Neurogenin 1 and Treatment with BDNF and GDNF: In Vitro and in Vivo Studies," The Journal of Neuroscience, 28, 12622-31.

Rubel, E. W. \& Fritzsch, B. (2002). "Auditory System Development: Primary Auditory Neurons and Their Targets," Annual Review of Neuroscience, 25, 51-101.

Schimmang, T., Minichiello, L., Vazquez, E., Jose, I. S., Giraldez, F., Klein, R. \& Represa, J. (1995). "Developing Inner-Ear Sensory Neurons Require TrkB and TrkC Receptors for Innervation of Their Peripheral Targets," Development, 121, 3381-3391.

Schuldiner, M., Eiges, R., Eden, A., Yanuka, O., Itskovitz-Eldor, J., Goldstein, R. S. \& Benvenisty, N. (2001). "Induced Neuronal Differentiation of Human Embryonic Stem Cells," Brain Research, 913, 201-205.

Shi, F. X., Corrales, C. E., Liberman, M. C. \& Edge, A. S. B. (2007). "BMP4 Induction of Sensory Neurons from Human Embryonic Stem Cells and Reinnervation of Sensory Epithelium," European Journal of Neuroscience, 26, 3016-3023.

Stern, C. D. (2006). "Neural Induction: 10 Years on Since the 'Default Model'," Current Opinion in Cell Biology, 18, 692-7.
Stone, J. S. \& Cotanche, D. A. (2007). "Hair Cell Regeneration in the Avian Auditory Epithelium," International Journal of Developmental Biology, 51, 633-647.

Troy, C. M., Brown, K., Greene, L. A. \& Shelanski, M. L. (1990). "Ontogeny of the Neuronal Intermediate Filament Protein, Peripherin, in the Mouse Embryo," Neuroscience, 36, 217-237.

Ulfendahl, M., Hu, Z., Olivius, P., Duan, M. \& Wei, D. (2007). "A Cell Therapy Approach to Substitute Neural Elements in the Inner Ear," Physiology \& Behavior, 92, 75-9.

Valensi-Kurtz, M., Lefler, S., Cohen, M. A., Aharonowiz, M., Cohen-Kupiec, R., Sheinin, A., Ashery, U., Reubinoff, B. \& Weil, M. (2010). "Enriched Population of PNS Neurons Derived from Human Embryonic Stem Cells as a Platform for Studying Peripheral Neuropathies," PloS One, 5, E9290.

Wilson, P. G. \& Stice, S. S. (2006). "Development and Differentiation of Neural Rosettes Derived from Human Embryonic Stem Cells," Stem Cell Reviews, 2, 67-77.

Wright, T. J. \& Mansour, S. L. (2003). "Fgf Signaling in Ear Development and Innervation," Current Topics in Developmental Biology, 57, 225-59.

Zhang, S. C., Wernig, M., Duncan, I. D., Brustle, 0. \& Thomson, J. A. (2001). "In Vitro Differentiation of Transplantable Neural Precursors from Human Embryonic Stem Cells," Nature Biotechnology, 19, 1129-1133. 